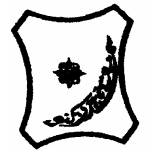

Bayero Journal of Pure and Applied Sciences, 9(2): 90 - 94

Received: June, 2016

Accepted: October, 2016

ISSN $2006-6996$

\title{
EVALUATION OF THE INFLUENCE OF MATERNAL PARITY ON NEONATAL ANTHROPOMETRIC PARAMETERS AMONG HAUSAS IN KANO STATE
}

*Datti, S., Taura, M.G., Modibbo, M.H., Adamu, L.H.,Tela, I.A., Gudaji, A., Asuku, A.Y. Department of Anatomy, Faculty of Basic Medical Sciences, College of Health Sciences, Bayero University P.O. Box 13793, Kano State, Nigeria

*Corresponding author: saaddatti@yahoo.com, +2347038234884

\begin{abstract}
Maternal Parity has been shown to increase the risk of adverse neonatal outcomes, such as intrauterine growth restriction (IUGR), prematurity, and mortality. The study was designed to evaluate the influence of maternal parity on neonatal anthropometric parameters among Hausas in Kano. Five hundred and twenty one subjects (mothers and babies) participated in the study. Questionnaire was used to collect the biodata, parity and other anthropometric variables (birth weight, birth length, head circumference, chest circumference, thigh circumference, mid upper arm circumference, hand length, hand breadth, foot length, foot breadth).The anthropometric variables were measured using standard procedures.One way ANOVA was used to determine the differences in neonatal variables across different categories of parity.SPSS (Statistical Package for Social Science) version 20 statistical software was used for data analyses. The result shows that the mothers within the 1st category of parity give birth to babies with lower birth weight and smaller thigh circumference when compared with $2^{\text {nd }}$, 3rd and 4th. However, in birth length, head circumference and chest circumference of the neonate the differences $(p<0.001)$ were observed only between $1^{\text {st }}$ and $2^{\text {nd }}$ category of parity. Moreover, the mid upper arm circumference has similar pattern with addition to $3^{\text {rd }}$ categories. In conclusion, the parity of the mother was found to influence the neonatal anthropometric variables.
\end{abstract}

Keywords: Maternal Parity, Neonatal Anthropometry, Hausas

\section{INTRODUCTION}

Maternal Parity has been shown to increase the risk of adverse neonatal outcomes, such as intrauterine growth restriction (IUGR), prematurity, and mortality (Ustaet al., 2008; Shah, 2010; Gibbset al., 2012). Nulliparity may confer risk through complicationsduring childbirth such as obstructed labour (Leeet al., 2011), whereas high parity has been linked to increased risk of hypertension,placenta previa, and uterine rupture (Shah, 2010). Severalstudies have hypothesized that in young mothers, maternal-fetal competition for nutrients and/or the mother's incomplete physical growth might contribute to adverse neonatal outcomes (Kramer and Lancaster, 2010). Older women experience an increase in the incidence of congenital abnormalities as well as maternal morbidities such as hypertension andgestational diabetes (Yogevet al., 2010; Carolan and Frankowska, 2011). However, some literature has suggested that controlling for socioeconomic status heavilyattenuates or eliminates associations of adolescence and of high parity with adverse outcomes (Sharma et al., 2008).It has been reported that primipara has higher relative risk of delivering low birth weight (LBW) babies in developing countries (Bisai et al., 2006;Lawoyin, 2007). In another study Elshibly and Schmalisch (2008) shows that primiparity is associated with an increased relative risk for LBW and that was distinctly higher when compared to the relative risk for LBW of other maternal characteristics.
Several studies relating the effect of mother's age and parity on birth weight indicate that parity is the most important factor of the two (Sanghvi and Patel, 2016).There is paucity of data concerning the influence of maternal parity on neonatal anthropometric variables. The study seek to investigate the influence of maternal parity on the neonatal anthropometric variables among Hausas in Kano

MATERIALS AND METHODS

Location of the study

The study was conducted in Murtala Muhammad Specialist Hospital, Kano. The state is located between latitude $12.2^{\circ}$ North and longitude $9.4^{\circ}$ East with the Kano city as the capital of the State. The State at present is the most populous in Nigeria, with over $9,000,000$ people (Barau, 2007).

The subjects of the study

The study population consisted of 521 healthy mothers and theirnewborns delivered by mothers of Hausa ethnic background. Full term neonates, singleton and delivered through spontaneous vaginal delivery (SVD), apparently healthy mothers were included. Caesarean section cases, twins, babies with major congenital malformations, infants born to diabetic mothers and mothers with pregnancy induced hypertension were excluded.

Ethical clearance was obtained from Hospital management board and informed consent was sought from the mother. 


\section{Instruments}

Tools used for the study include: - Questionnaires, Digital weighing scale (Model: ACS - 20, Country: China), Sliding vernier caliper and plastic measuring tape.

\section{METHODS}

The study subjectswere measured for the following variables over a period of three months (February to April 2013), using the left side of the body (Allbrook 1961; Martin and Sallar 1959):

Birth Weight (BW) in Kg: Way Master weighing scale was used to measure the birth weight with the capacity of $13 \mathrm{~kg} \times 50 \mathrm{~g}$.

Head circumference (HC) in cm: Head circumference was measured at the largest frontal occipital plane between glabella anteriorly and along the most prominent point posteriorly using a measurement tape to the nearest $0.1 \mathrm{~cm}$

Chest circumference (CC) in $\mathbf{~ c m}$ : was measured using an inelastic tape as horizontal circumference of the chest at the level of the nipples at the end phase of expiration

Mid upper arm circumference (MUAC) in cm: Was measured at the midpoint between the tip of acromion process and olecranon process of the left upper arm using inelastic tape

Birth length (BL) in $\mathbf{~ c m}$ : Measured as the projective distance between the highest point on the head (vertex), and the most posterior projecting point of the heel, using infant measuring mat in supine position.

Hand length (HL) in $\mathbf{~ c m}$ : Measured from the midpoint of the distal wrist crease, to the tip of the middle finger using a plastic measuring tape (palmer surface of the hand in supine position).

Hand breadth (HB) in $\mathbf{c m}$ : Measured from the head of the 5th to 2nd metacarpal using a sliding vernier caliper (palmer surface of the hand in supine position).

Foot length (FL) in $\mathbf{~ c m : ~ M e a s u r e d ~ a s ~ a ~ s t r a i g h t ~}$ distance between the most posterior projecting point of the heel and anterior projecting point (the end of 1st or 2nd toe) using a plastic measuring tape (Planter view of the sole of the foot in supine position).

Foot breadth (FB) in $\mathbf{~ c m}$ : Measured at the widest point of the sole, which is from the metatarsophalangeal joint of the 1st metatarsal and that of the 5th metatarsal of the foot using a sliding vernier calliper

All the measurements were taken by one investigator, measurements were taken twice

Data analysis

SPSS (Statistical Package for Social Science) version 20 statistical software was used for data analyses. The data were expressed as Mean \pm Standard Deviation (S.D). $P<0.05$ was considered statistically significant.

\section{RESULTS}

The result for differences of birth weight across different categories of parity is presented in Table 1. There is significant difference in birth weight between $1^{\text {st }}$ category and $2^{\text {nd }}$ parity category, in addition differences were also observed between $1^{\text {st }}$ and $3^{\text {rd }}$ parities categories.

Table 1: Variation of birth weight with parity in study subjects

\begin{tabular}{|c|c|c|c|c|c|c|}
\hline \multirow[t]{2}{*}{ Variables } & \multicolumn{4}{|c|}{ Parity } & \multirow[t]{2}{*}{$\mathbf{F}$} & \multirow[t]{2}{*}{$\mathbf{P}$} \\
\hline & $1^{\text {st }}$ & $2^{\text {nd }}$ & $3^{\text {rd }}$ & $4^{\text {th }}$ & & \\
\hline Birth weight & $3.25 \pm 0.467^{a, b}$ & $3.66 \pm 0.518^{\mathrm{a}}$ & $3.60 \pm 0.497^{b}$ & $3.60 \pm 0.476$ & 25.003 & $<0.001$ \\
\hline \multicolumn{7}{|c|}{$\begin{array}{l}\text { Similar superscripts indicate significant difference between the groups at } \mathrm{P}<0.05 .1^{\text {st }} \text { parity; delivered } 1-3 \text { times, } \\
2^{\text {nd }} \text { parity; delivered } 4-6 \text { times, } 3^{\text {rd }} \text { parity; delivered } 7-9 \text { times and } 4^{\text {th }} \text { parity; delivered } 10 \text {-above times }\end{array}$} \\
\hline \multicolumn{3}{|c|}{$\begin{array}{l}\text { The result for differences of neonatal variables across } \\
\text { different categories of parity is presented in Figure } 1 \\
\text { and } 2 \text {. The mothers within the 1st category of parity } \\
\text { show significant differences }(p<0.001) \text { in the BW } \\
\text { and TC of their neonates when compared with } 2 \text { nd, }\end{array}$} & \multicolumn{4}{|c|}{$\begin{array}{l}\text { 3rd and 4th. However, in } \mathrm{BL}, \mathrm{HC} \text { and } \mathrm{CC} \text { of the } \\
\text { neonates the differences }(\mathrm{p}<0.001) \text { were observed } \\
\text { only between 1st and 2nd category of parity. } \\
\text { Moreover, similar pattern was observed in MUAC with } \\
\text { regards to mothers with parity of seven to nine. }\end{array}$} \\
\hline
\end{tabular}




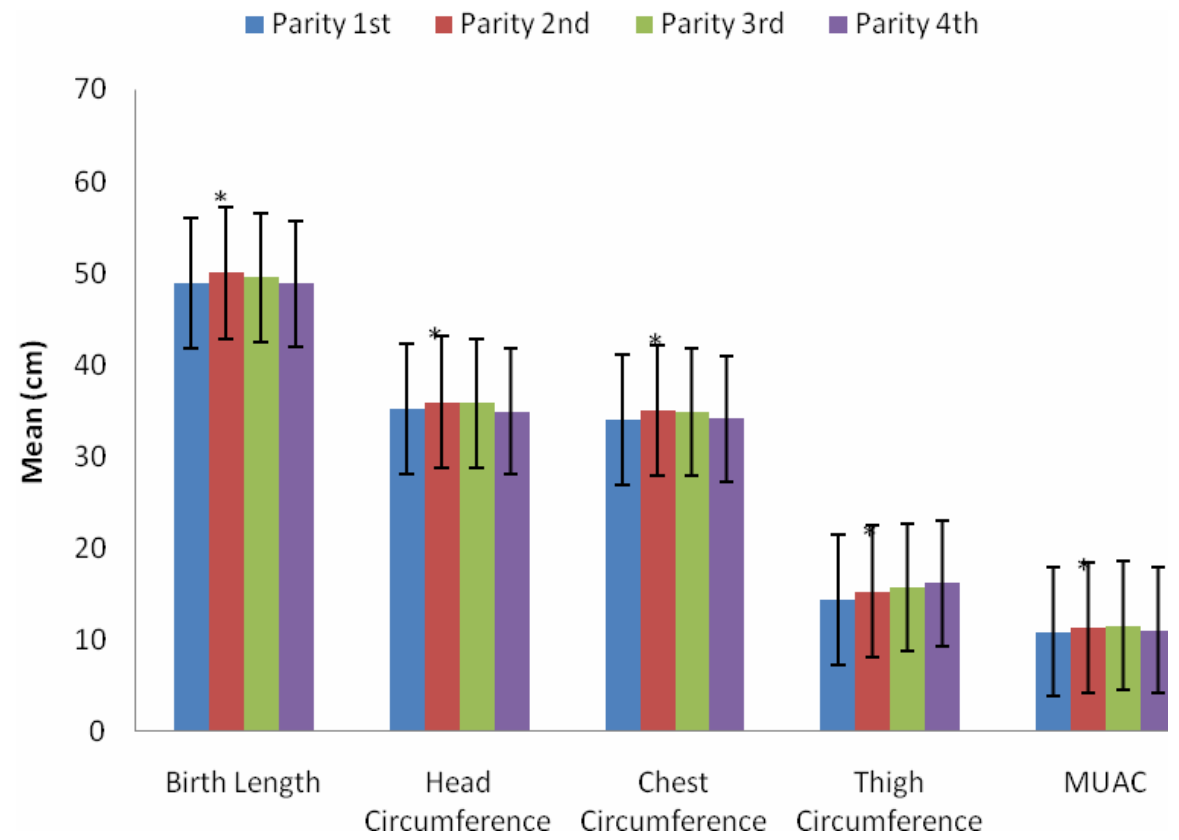

Fig 1: Differences in birth length and body circumferences across different categories of parities $(* p<0.05)$

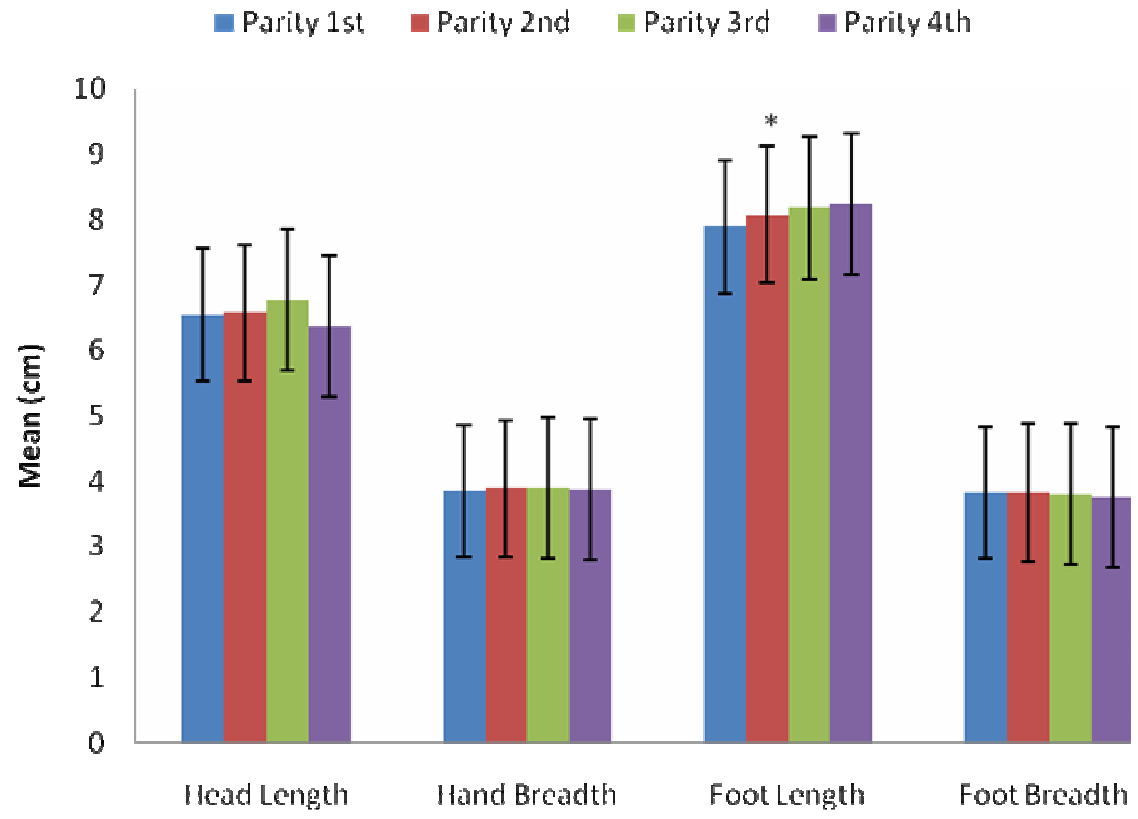

Fig 2: Differences in neonatal hand and foot variables across different categories of parities $(* p<0.05)$

\section{DISCUSSION}

The current study explores the differences in neonatal variables among different categories of parity. The result shows significant decreasesin neonatal variable of $1^{\text {st }}$ parity category compared with others. The findings complement several studies relating the effect of mother's parity on birth weight indicating that parity is the more important factor affecting birth weight and higher the parity, the more likely the lower the birth weight (Warburton and Naylor, 1971; Sanghvi and Patel, 2016). Study from other developing country indicates that birth order was one of the major factors affecting birth weight; women who were pregnant for the second and third time gave birth to neonates with higher birth weights, while women with first gravidity gave birth to neonates with lower birth weights.A possible explanation of lower birth weight among first-born infants could be a consequence of biological immaturity of the mothers as compared to later-born infants (Bisai et al., 2006). 
Furthermore, other variables like $\mathrm{BL}, \mathrm{HC}, \mathrm{CC}$ and MUAC indicate similar trend as observed in the BW. This can also be linked to consequence of biological immaturity which usually happenes in the early born child compared to the later ones. Severalstudies have hypothesized that in young mothers, maternal-foetal competition for nutrients and/or the mother's incomplete physical growth might contribute to adverse neonatal outcomes (Kramer and Lancaster, 2010).

\section{CONCLUSION}

The study determined the relationship between maternal parity and neonatal anthropometric parameters among Hausas in Kano State. The finding

\section{Contributions of authors}

\begin{tabular}{|c|c|c|c|c|c|c|}
\hline Authors & Lit. rev & Methodology & Result & Discussion & Conclusion & References \\
\hline Datt S & $\checkmark$ & $\checkmark$ & $\checkmark$ & $\checkmark$ & $\checkmark$ & $\checkmark$ \\
\hline Taura MG & & & & $\checkmark$ & & \\
\hline Modibbo $\mathrm{MH}$ & & & $\checkmark$ & & & \\
\hline Adamu LH & & $\checkmark$ & $\checkmark$ & $\checkmark$ & & \\
\hline Tela IA & & $\checkmark$ & & & & \\
\hline Gudaji A & & & $\checkmark$ & & & \\
\hline Asuku AY & & & & $\checkmark$ & & \\
\hline
\end{tabular}

shows a sharp increase in anthropometric measurement from $1^{\text {st }}$ parity to $2^{\text {nd }}$ parity with slight decrease from $3^{\text {rd }}$ to $4^{\text {th }}$ parity. This is possibly as a result of maternal- foetal competition for nutrients and/or the mother's incomplete physical growthin young mothersand might contribute to adverse neonatal outcomes(Kramer and Lancaster, 2010).

\section{Acknowledgements}

My sincere thanks go to the Management of Murtala Muhammad Specialist Hospital Kano for their understanding and support given to us during the data collection. I also acknowledge the cooperation given to me by the subjects.

\section{Area of conflicts}

- None

\section{Reference}

Allbrook, D. (1961): The estimation of stature in British and East African males based on tibial and ulna bone lengths. Journal of Forensic Medicine, 8: 15-28.

Barau, A. S. (2007): The Great Attractions of Kano. Research and Documentation publications. Research and Documentation Directorate, Government House Kano. ISBN 978-8109-33-0

Bisai, S., Sen, A., Mahalanabis, D., Datta, N., Bose, K. (2006): The Effect of Maternal Age and Parity on Birth Weight Among Bengalees of Kolkata, India. Human Ecology Special, 14, 139-143

Carolan, M. and Frankowska, D. (2011): Advanced maternal age and adverse perinatal outcome: a review of the evidence. Midwifery, 27(6):793801.

Elshibly, E.M. and Schmalisch, G. (2008): Correlation between anthropometric measures and birth weight of infants: Value in measuring actual birth weight. American Journal of Perinatology, 25, 135-139.

Gibbs, C.M., Wendt, A., Peters, S. and Hogue, C.J. (2012): The impact of early age at first childbirth on maternal and infant health. Paediatric and Perinatal Epidemiology, 26(Suppl 1):259 284.

Kramer, K.L. and Lancaster, J.B. (2010): Teen motherhood in cross-cultural perspective. Annals of Human Biology, 37(5):613-628.

Lawoyin, T.O. (2007): Infant and maternal deaths in rural south west Nigeria: a prospective study. African Journal of Medical Sciences, 36, 235-241.

Lee, A.C., Mullany, L.C., Tielsch, J.M., Katz, J., Khatry, S.K., LeClerq,S.C., Adhikari, R.K. andDarmstadt, G.L. (2011): Community-based stillbirth rates and risk factors in rural Sarlahi, Nepal.
International Journal ofGynaecology andObstetrics, 113(3):199-204.

Martin, R. and Sallar, K. (1959): Lehrbuch der Anthropologie in systematischer. FischerDarstellung, Stuttgart.

Sanghvi, J.Y. and Patel, A. (2016): Study of neonatal outcome in relation to maternal nutrition and anthropometry. International Journal of Contemporary Paediatrics, 3(2): 524-529.

Shah, P.S. (2010): Parity and low birth weight and preterm birth: a systematicreview and metaanalyses. Acta Obstetricia et Gynecologica Scandinavica, 89(7):862-875.

Sharma, V., Katz, J., Mullany, L.C., Khatry, S.K., LeClerq, S.C., Shrestha, S.R., Darmstadt, G.L. and Tielsch, J.M. (2008):Young maternal age and the risk of neonatal mortality in rural Nepal. Archives of Pediatrics and Adolescent Medicine, 162(9):828-835.

Taffa, N. (2003): A comparison of pregnancy and child health outcomes between teenage and adult mothers in the slums of Nairobi, Kenya. International Journal of Adolescent Medicine and Health, 15(4):321-329.

Usta, I.M., Zoorob, D., Abu-Musa, A., Naassan,G. and Nassar, A.H. (2008): Obstetric outcome of teenage pregnancies compared with adult pregnancies. Acta Obstetricia et Gynecologica Scandinavica, 87(2):178-183.

Warburton, D. and Naylor, A.F.(1971): The effect of of parity on placental weight and birth weight: an immunological phenomenon? A report of the collaborative study of cerebral palsy. American Journal of Human Genetic, 23: 41-54

Yogev, Y., Melamed, N., Bardin, R., Tenenbaum-Gavish, K., Ben-Shitrit, G. and Ben- Haroush, A. (2010): Pregnancy outcome at extremely advanced maternal age. American Journalof ObstetricsGynaecology, 203(6):558e.1-558-e.7. 


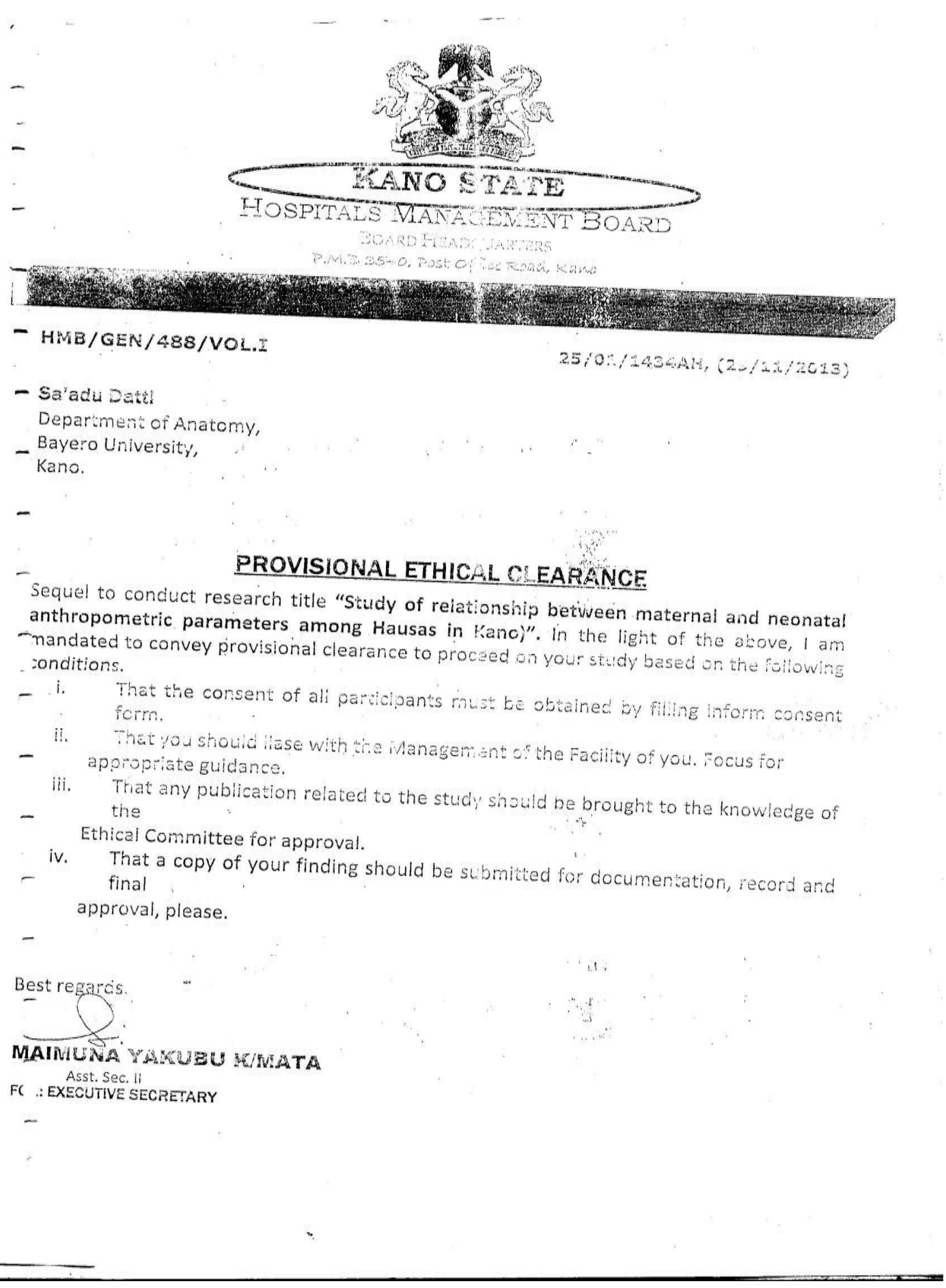

